\title{
The new impact factor of World Psychiatry
}

\author{
Mario MaJ \\ President, World Psychiatric Association
}

World Psychiatry recently received its new impact factor, 4.375. It is now in the top 10 of journals of general psychiatry and in the top 20 of all journals of clinical psychiatry, biological psychiatry and psychopharmacology.

The journal is now published in five languages: English, Spanish, Chinese, Russian and French. Selected articles or abstracts are also translated in other languages, such as Japanese, Polish and Romanian, and posted on the website of the WPA and/or relevant WPA Member Societies. All issues of the journal can be freely downloaded from PubMed Central (www.ncbi.nlm.nih.gov/pmc/journals/297) and the WPA website (www.wpanet.org). The paper version of the journal reaches more than 33,000 psychiatrists in 121 countries, being for many thousands of them the only accessible international psychiatric journal.

In compliance with a decision made by the WPA Executive Committee in 2001, the journal does not contain advertisements.

The publication of World Psychiatry has two main objectives, which make it different from most, possibly all, other international psychiatric journals. The first objective is to reach as many psychiatrists of the various countries of the world as possible, disseminating information on recent significant clinical, service and research developments in a language that can be assimilated by the vast majority of them. Relevance to everyday clinical practice of the average psychiatrist and usefulness to foster his/her professional growth are the two main criteria by which an article submitted to World Psychiatry is evaluated. In addition to this, the style of the paper must be simple and clear.

The second objective is to give voice to psychiatrists of all regions of the world, encouraging submission of research papers, commentaries and reports on innovative service modalities. Among the articles published in World Psychiatry in the last two years, $21 \%$ had at least one author from a low or middle income country, including seven with at least one author from Africa.

Is there the need for a journal like World Psychiatry? Are there, at present, problems with the dissemination of information on clinical, service and research developments to psychiatrists worldwide, with the contribution by psychiatrists from non-Western countries to international psychiatric journals, and with the clinical relevance of part of the scientific research which is published in psychiatric journals? I think that each of these questions can be answered positively.

The access of the average psychiatrist to international psychiatric journals is becoming more and more difficult. This is not only due to financial reasons (the vast majority of psychiatrists of the world cannot afford a personal subscription to even one international psychiatric journal, and many academic centers are now reducing the number of journals to which they subscribe), but also to the objective difficulty in understanding the language, the concepts and the technical details of several articles, and the lack of motivation to read papers which do not have an obvious clinical relevance. The traditional gap between the small circle of researchers and the multitude of psychiatric practitioners is becoming wider and wider.

That only very few psychiatrists from non-Western countries are able to contribute to international psychiatric journals has been repeatedly documented. In addition to problems with language and research traditions, the fact is that research in psychiatry is becoming an increasingly complex and expensive activity. The contents of our main scientific journals increasingly consist of sophisticated papers reporting on neuroimaging, genetic, or molecular biology research carried out in well-resourced academic departments of a limited number of Western countries. The traditional gap between developed and developing countries in conducting psychiatric research is becoming wider and wider.

The gap between the issues addressed by part of published psychiatric research and those perceived by clinicians as relevant to their everyday clinical practice is probably also increasing. Biological research in psychiatry is crucial for the advancement of knowledge and for the development of new treatment modalities. However, we have been probably too liberal in the last few decades in accepting biological research papers for publication in international psychiatric journals. A look at some papers published 10 or 15 years ago may be, in this respect, instructive: the message they conveyed is now completely obsolete, not so much because new technologies have developed in the meantime, but because the findings themselves (usually, a small although statistically significant difference between a sample of patients with a psychiatric diagnosis and a sample of healthy controls, with respect to the mean values for one or more biological variables) were of no actual scientific and clinical relevance.

Given the above-mentioned two objectives, it is understandable that the ingredients and the overall flavor of each issue of World Psychiatry are different from those of other international psychiatric journals. An important ingredient is represented by the forums, which are particularly appreciated by our readership and usually attract several quotations in the international literature. Among the most successful forums we published in the past few years are those on the concept of mental disorder (1), on conflicts of interests in psychiatry (2), on steps, challenges and lessons in developing community mental health care (3), on the role of functional 
impairment in the diagnosis of mental disorders (4), on the lessons learned from pragmatic trials of psychotropic drugs (5), and on early intervention in psychosis (6). Each of these forums included participants from all continents. Another special ingredient is represented by the mental health policy papers, providing information on innovative experiences in mental health care from various regions $(7,8)$, or addressing issues, such as psychiatric brain drain (9) or burnout in psychiatrists (10), which are rarely covered in international psychiatric journals.

Among research reports, we give priority to international and national multicenter studies providing data on epidemiology of mental disorders in various countries or testing innovative modalities of mental health service delivery or psychosocial interventions. In the past few years, we hosted for instance two of the main reports on the World Mental Health Survey Initiative $(11,12)$; the first community study of the prevalence and correlates of mental disorders in Iraq (13), which attracted the attention of the International Herald Tribune, the Washington Post and the New York Times; and the first controlled trial of a classroom-based intervention for children and adolescents exposed to war experiences in the Middle East (14).

Our review articles are all invited and deal with issues of great interest to psychiatrists worldwide. Among the articles which were most appreciated by our readership in the past few years, are those on grief and bereavement (15), on cultural factors in psychiatric diagnosis (16), on self-stigma in people with severe mental disorders (17), on neurobehavioural sequelae of traumatic brain injury (18), and on diagnosis and treatment of attention-deficit/hyperactivity disorder in adults (19).

The forum of one of the latest issues of World Psychiatry was entitled "Are psychiatrists an endangered species?" (20). Indeed, we and our profession are stigmatized in many countries of the world. This is certainly related to our difficulty to convey the new image of psychiatry: the image of an integrative discipline, which deals with a broad range of disorders, including some that are very common in the population, using interventions that are at least as effective as those available to most other branches of medicine. However, it would not be fair to state that psychiatry has just a problem with promoting more successfully its new image. It has to be acknowledged that our profession also has a problem, in several contexts in many countries, with matching up to this new image in the reality of clinical practice, research and training.

Our hope is that the dissemination of World Psychiatry will contribute to upgrade the image and the reality of psychiatry in as many countries of the world as possible.

\section{References}

1. Wakefield JC. The concept of mental disorder: diagnostic implications of the harmful dysfunction analysis. World Psychiatry 2007;6:149-56.

2. Fava GA. Financial conflicts of interest in psychiatry. World Psychiatry 2007;6:19-24.

3. Thornicroft G, Tansella M, Law A. Steps, challenges and lessons in developing community mental health care. World Psychiatry 2008;7:87-92.

4. Üstün B, Kennedy C. What is "functional impairment"? Disentangling disability from clinical significance. World Psychiatry 2009;8: 82-5.

5. Fleischhacker WW, Goodwin GN. Effectiveness as an outcome measure for treatment trials in psychiatry. World Psychiatry 2009;8: 23-7.

6. McGorry PD, Killackey E, Yung A. Early intervention in psychosis: concepts, evidence, and future directions. World Psychiatry 2008; 7:148-56.

7. Alem A, Jacobsson L, Hanlon C. Community-based mental health care in Africa: mental health workers' views. World Psychiatry 2008; 7:54-7.

8. $\mathrm{Ng} \mathrm{C}$, Herrman $\mathrm{H}$, Chiu E et al. Community mental health care in the Asia-Pacific region: using current best-practice models to inform future policy. World Psychiatry 2009;8:49-55.

9. Gureje O, Hollins S, Botbol M et al. Report of the WPA Task Force on Brain Drain. World Psychiatry 2009;8:115-8.

10. Kumar S. Burnout in psychiatrists. World Psychiatry 2007;6:186-9.

11. Kessler RC, Angermeyer M, Anthony JC et al. Lifetime prevalence and age-of-onset distribution of mental disorders in the World Health Organization's World Mental Health Survey Initiative. World Psychiatry 2007;6:168-76.

12. Wang PS, Angermeyer M, Borges G et al. Delay and failure in treatment seeking after first onset of mental disorders in the World Health Organization's World Mental Health Survey Initiative. World Psychiatry 2007;6:177-85.

13. Alhasnawi S, Sadik S, Rasheed M et al. The prevalence and correlates of DSM-IV disorders in the Iraq Mental Health Survey (IMHS). World Psychiatry 2009;8:97-109.

14. Karam EG, Fayyad J, Nasser Karam A et al. Effectiveness and specificity of a classroom-based group intervention in children and adolescents exposed to war in Lebanon. World Psychiatry 2008;7:103-9.

15. Zisook S, Shear K. Grief and bereavement: what psychiatrists need to know. World Psychiatry 2009;8:67-74.

16. Alarcon RD. Culture, cultural factors and psychiatric diagnosis: review and projections. World Psychiatry 2009;8:131-9.

17. Corrigan PW, Larson JE , Rusch N. Self-stigma and the "why try" effect: impact on life goals and evidence-based practices. World Psychiatry 2009;8:75-81.

18. McAllister TW. Neurobehavioural sequelae of traumatic brain injury: evaluation and management. World Psychiatry 2008;7:3-10.

19. Faraone SV, Anthsel KM. Diagnosing and treating attention-deficit/ hyperactivity disorder in adults. World Psychiatry 2008;7:131-6.

20. Katschnig H. Are psychiatrists an endangered species? Observations on internal and external challenges to the profession. World Psychiatry 2010;9:21-8. 